\title{
Modeling of the minimum cutting thickness in micro cutting with consideration of the friction around the cutting zone
}

(C) The Author(s) 2019. This article is published with open access at link.springer.com and journal.hep.com.cn

\begin{abstract}
Friction modeling between the tool and the workpiece plays an important role in predicting the minimum cutting thickness during TC4 micro machining and finite element method (FEM) cutting simulation. In this study, a new three-region friction modeling is proposed to illustrate the material flow mechanism around the friction zone in micro cutting; estimate the stress distributions on the rake, edge, and clearance faces of the tool; and predict the stagnation point location and the minimum cutting thickness. The friction modeling is established by determining the distribution of normal and shear stress. Then, it is applied to calculate the stagnation point location on the edge face and predict the minimum cutting thickness. The stagnation point and the minimum cutting thickness are also observed and illustrated in the FEM simulation. Micro cutting experiments are conducted to validate the accuracy of the friction and the minimum cutting thickness modeling. Comparison results show that the proposed friction model illustrates the relationship between the normal and sheer stress on the tool surface, thereby validating the modeling method of the minimum cutting thickness in micro cutting.
\end{abstract}

Keywords tool friction, minimum cutting thickness, finite element method, tool edge radius, micro cutting

Received February 27, 2019; accepted July 5, 2019

Tianfeng ZHOU ( $(\mathbb{)})$, Zhiqiang LIANG, Xibin WANG

Key Laboratory of Fundamental Science for Advanced Machining, Beijing Institute of Technology, Beijing 100081, China

E-mail: zhoutf@bit.edu.cn

Ying WANG, Benshuai RUAN

School of Mechanical Engineering, Beijing Institute of Technology, Beijing 100081, China

\section{Introduction}

\subsection{Research on the minimum cutting thickness}

With the fast increasing demand of miniature components and products in fields such as aerospace, medical equipment, and electronic communication devices, the manufacturing methods of micro-scale parts have become a research hotspot. Micro cutting has wide applications in manufacturing micro and ultra-precision components because of its prominent capabilities in versatile material processing and complex 3D surface machining. The minimum cutting thickness is an important parameter in micro cutting because it influences machining accuracy and tool wear. Therefore, building a prediction model for the minimum cutting thickness is essential to understand the mechanics of micro cutting and improve the quality of processing. Friction plays a dominant role in predicting the minimum cutting thickness [1]. Currently, the determination of the minimum cutting thickness primarily depends on experiments $[2,3]$. However, experimental approaches have many limitations, such as weak universality and time consuming. Accordingly, developing a prediction method for the minimum cutting thickness is valuable. Agmell et al. [4] proposed a model that builds a connection between the minimum cutting thickness and the stagnation point. Atlati et al. [5] presented a numerical model that describes the material flow around the cutting edge. Ee et al. [6] proposed that cutting parameters influence the stagnation point. This paper further discusses the friction around the cutting zone to determine the stagnation point location from the perspective of the minimum cutting thickness.

\subsection{Theoretical analysis of the friction in micro cutting}

Amontons's rules present good approximations for clean, dry, and smooth surfaces sliding in air [7]. However, previous cutting tests revealed the presence of friction 
between the metal in the cutting process and the metal pair. Amontons's rules fail to capture the relationship between normal force and shear force under usual conditions where the true area of contact $A_{\mathrm{T}}$ is only a small portion of the surface area of contact $A_{\mathrm{S}}\left(A_{\mathrm{T}} \ll A_{\mathrm{S}}\right)$.

Zorev [8] presented the distributions of shear and normal stress on the rake face of the cutting tool, as shown in Fig. 1. The contact area on the rake face of the cutting tool can be divided into two sections: Sticking section $(A B)$ and sliding section $(B C)$. In the sticking section $(A B)$, the shear stress is independent from other factors and only equal to the shear strength of the metal. In the sliding section $(B C)$, no relation exists between the friction coefficient and normal stress. Shaw [9] also achieved the same conclusion, with the experiment proving that the friction coefficient is a constant in the sliding section. Moufki et al. [10] presented a temperature-dependent friction model of metal pair in the manufacturing process. Wallace and Boothroyd [11] also obtained similar conclusions.

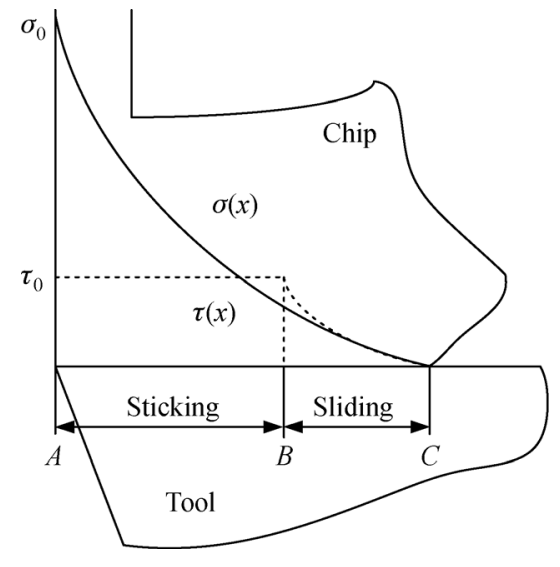

Fig. 1 Zoerv's model of the normal and shear stress distribution on the rake face [8].

1.3 Finite element method modeling of friction in micro cutting

Researchers also proposed several approaches to establish a friction model by finite element simulation of metal cutting. Coulomb's law of friction coefficient was researched by Strenkowski and Moon [12] $(\mu=0.2)$, as well as by Lin and Lo [13] $(\mu=0.1)$. Zorev's stickingsliding friction modeling is also widely applied. In the research conducted by Liu and Guo [14], Zhang and Bagchi [15], the following formulas are used and the programs automatically determine the sliding and sticking sections:

$$
\tau= \begin{cases}\mu \sigma, & \tau<\tau_{\max }, \\ \tau_{\max }, & \tau \geqslant \tau_{\max },\end{cases}
$$

where $\mu$ represents the friction coefficient, $\sigma$ represents the normal stress, $\tau$ represents the shear stress and $\tau_{\max }$ represents the maximum shear stress.

In Refs. [12-14], measured cutting forces were used. The expression of the friction model is shown as follows:

$$
\mu=c \frac{F_{\mathrm{t}}+F_{\mathrm{c}} \tan \alpha}{F_{\mathrm{c}}-F_{\mathrm{t}} \tan \alpha},
$$

where $F_{\mathrm{c}}$ and $F_{\mathrm{t}}$ are measured cutting and thrust forces, respectively, $\alpha$ is rake angle, and $c$ is a coefficient.

However, the above-mentioned friction models are only suitable for ideal sharp tools and are not adapted to the micro cutting process where the tool edge radius cannot be ignored. Therefore, those models that do not consider the edge radius are unsuitable for micro cutting. Accordingly, this research concentrates on this question.

In this paper, we proposed a theoretical method to predict the minimum cutting thickness during micro cutting. The method was thoroughly explored and discussed by establishing a friction modeling around the cutting zone. The cutting zone includes the tool-chip interface (Region I), the tool-workpiece interface (Region II), and the tool-edge/workpiece interface (Region III). The friction modeling was established by determining the distributions of normal and shear stress to identify the stagnation point location on the edge face and predict the minimum cutting thickness. Finally, micro cutting experiments were conducted to validate the accuracy of the friction model, where the minimum cutting thickness values achieved through modeling and experiments were compared. Results showed that the friction model is efficient in predicting the minimum cutting thickness and that the method developed in this study can be applied for different tool edge radii.

\section{Modeling of the minimum cutting thickness in micro cutting}

\subsection{Material flow and friction around the cutting zone}

During cutting, the workpiece material flows along the cutting tool surface and is separated into two parts: The chip and the machined workpiece. The separated material flows in the two inverse directions along the cutting tool. The material velocity is zero at a certain point because any cutting tool has a round edge. This certain point is conventionally called the "stagnation point," as shown in Fig. 2.

In the cutting process, the location of the stagnation point is a significant factor in evaluating the minimum cutting thickness. A method for determining the location of the stagnation point is to build the friction modeling at the tool-chip/workpiece interface. As shown in Fig. 3, the interface was divided into three sections: Tool-chip interface (Region I), tool-workpiece interface (Region II), and tool edge--workpiece interface (Region III). 


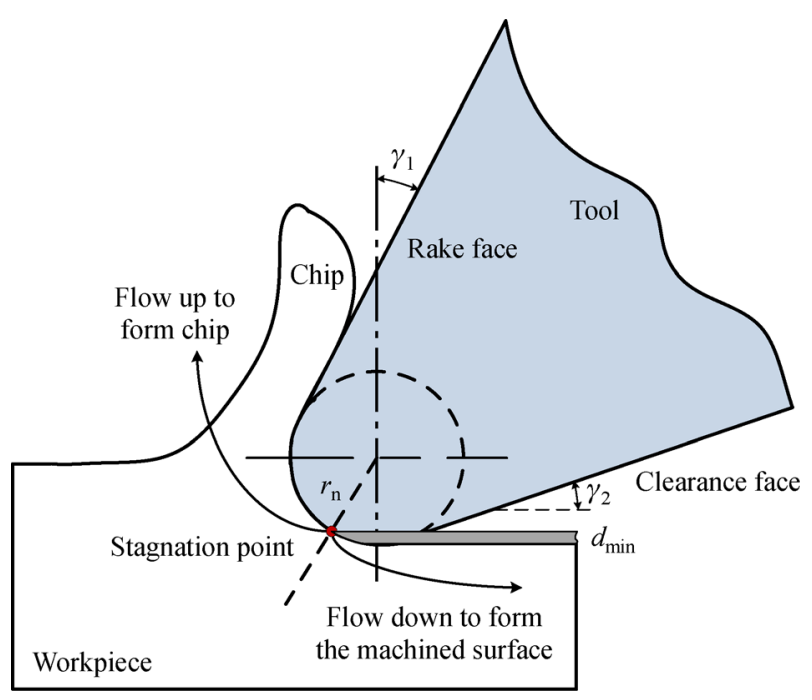

Fig. 2 Material flow around the cutting zone.

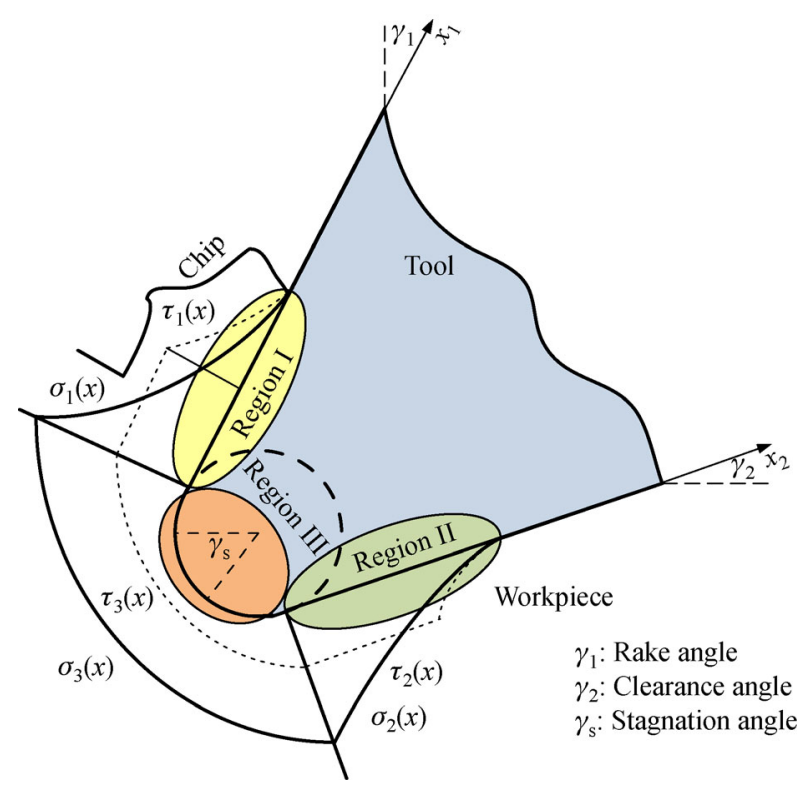

Fig. 3 Stress distributions around the cutting zone.

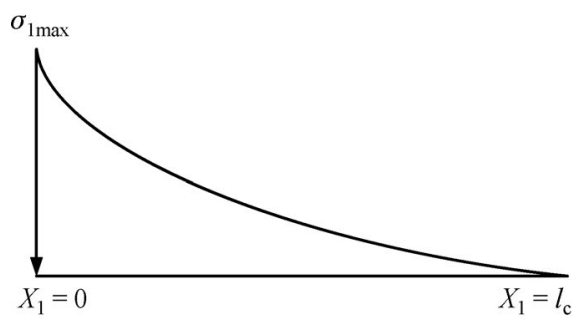

(a)

\subsection{Modeling of the minimum cutting thickness}

In Region I, the tool surface and the workpiece material are considered to have full contact on the rake face, where the workpiece material faces shearing. In this region, from the point of contact between the rake face and the tool edge $\left(X_{1}=0\right)$ to the point at which the workpiece material is separated from the rake face $\left(X_{1}=l_{\mathrm{c}}\right)$, the tool and workpiece face are both exposed to sticking and sliding friction conditions. In Region II, the situation is the same as that in Region I.

The sticking-sliding friction modeling along the rake face and clearance face, as well as the linear stress distributions along the round edge of the tool, are exhibited in Figs. 4 and 5. Many researchers have verified similar stress distributions in Regions I and II. The edge radius of sharp tools could be assumed as very small or relatively small depending on the tool specification. Then, the tool is assumed to be its fresh state of geometry. As shown in Figs. 4 and 6, one end of this region is the beginning of the rake face and the other end is the beginning of the clearance face. The normal and shear stress changes are shown in Fig. 5.

In Region I, the normal stress distribution is assumed to satisfy the polynomial as follows:

$$
\sigma_{1}\left(x_{1}\right)=\sigma_{1 \max }\left(1-\frac{x_{1}}{l_{\mathrm{c} 1}}\right)^{n},
$$

where $\sigma_{1}$ represents the normal stress on the rake face, $x_{1}$ represents the normal stress on the rake face, $\sigma_{1 \max }$ represents the maximum normal stress on the rake face, $l_{\mathrm{c} 1}$ represents the length of the rake face, and $n$ is a coefficient.

The expression of shear stress is

$$
\tau_{1}\left(x_{1}\right)=\left\{\begin{array}{l}
\tau_{1 \max }, \\
\mu_{1} \sigma_{1}\left(x_{1}\right),
\end{array}\right.
$$

where $\tau_{1}$ represents the shear stress on the rake face, $\tau_{1 \max }$ represents the maximum shear stress on the rake face, and $\mu_{1}$ represents the friction coefficient.

In Region II, the normal stress distribution is assumed to satisfy the polynomial as follows:

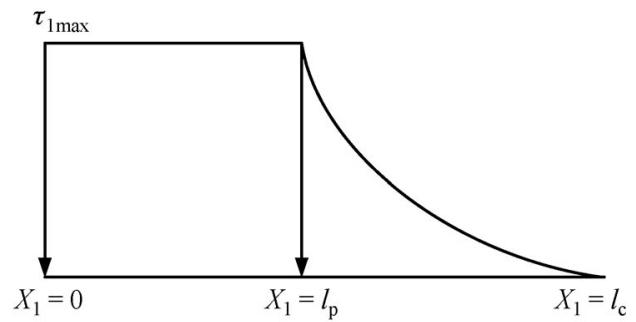

(b)

Fig. 4 (a) Normal stress and (b) shear stress on the rake face and clearance face. 


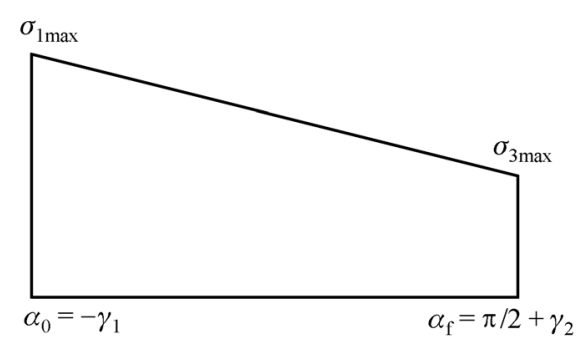

(a)

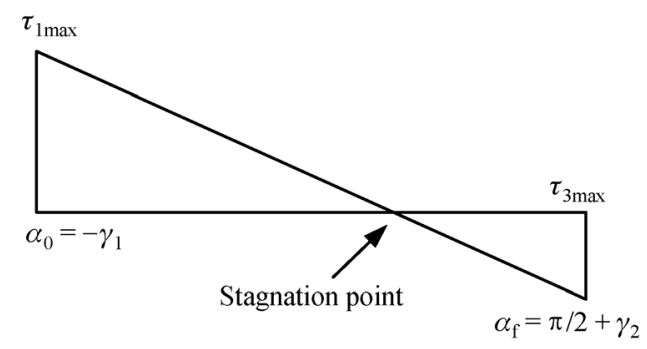

(b)

Fig. 5 Stress distributions in Region III: (a) Normal stress distribution; (b) shear stress distribution.

$$
\sigma_{2}\left(x_{2}\right)=\sigma_{2 \max }\left(1-\frac{x_{2}}{l_{\mathrm{c} 2}}\right)^{n},
$$

where $\sigma_{2}$ represents the normal stress on the clearance face, $x_{2}$ represents the normal stress on the clearance face, $\sigma_{2 \max }$ represents the maximum normal stress on the clearance face, and $l_{\mathrm{c} 2}$ represents the length of the clearance face.

The expression of shear stress is

$$
\tau_{2}\left(x_{2}\right)=\left\{\begin{array}{l}
\tau_{2 \max } \\
\mu_{2} \sigma_{2}\left(x_{2}\right)
\end{array}\right.
$$

where $\tau_{2}$ represents the shear stress on the clearance face, $\tau_{2}$ max represents the maximum shear stress on the clearance face, and $\mu_{2}$ represents the friction coefficient.

Region III is the tool edge face, which is the curvilinear section between Regions I and II, as shown in Fig. 6. Considering that the stress distribution is uniform around

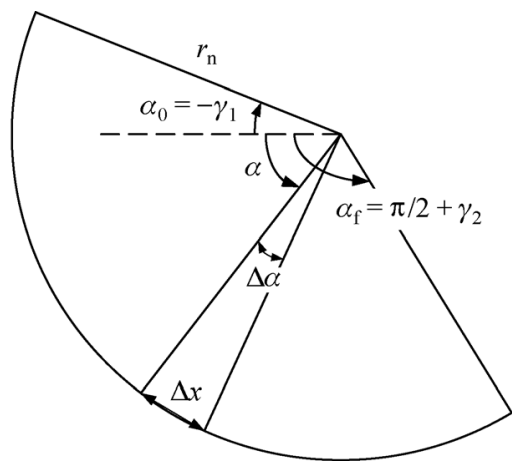

Fig. 6 Illustration of the edge face.

the tool edge face, as shown in Fig. 7, we can assume that the stress changes linearly in the third contact region.

The normal stress starts from $\sigma_{1 \max }$ at $\alpha=\gamma_{1}$ and then decreases linearly to $\sigma_{2 \max }$ at $\alpha=a / 2+\gamma_{2}$. The shear stress starts from $\tau_{1 \max }$ at $\alpha=\gamma_{1}$ and then decreases linearly to $\tau_{2 \max }$ at $\alpha=\pi / 2+\gamma_{2}$. Accordingly, normal stress $\sigma_{3}$ and shear stress $\tau_{3}$ in Region III can be expressed as follows:

$$
\sigma_{3}(\alpha)=\frac{\left(\sigma_{2 \max }-\sigma_{1 \max }\right) \alpha+\left[\gamma_{1} \sigma_{2 \max }+\left(\pi / 2+\gamma_{2}\right) \sigma_{1 \max }\right]}{\pi / 2+\gamma_{1}+\gamma_{2}},
$$

$$
\tau_{3}(\alpha)=\frac{\tau_{2 \max }+\tau_{1 \max } \alpha\left[\gamma_{1} \tau_{2 \max }-\left(\pi / 2+\gamma_{2}\right) \tau_{1 \max }\right]}{\pi / 2+\gamma_{1}+\gamma_{2}} .
$$

As shown in Fig. 2, the direction of chip flow is opposite to the direction of machined workpiece. As such, the direction of the maximum shear stress at the clearance face $\left(\tau_{2 \max }\right)$ is opposite to the rake face shear stress $\left(\tau_{1 \max }\right)$, which generates the stagnation point at the edge face. The stagnation angle can be found as follows:

$$
\gamma_{3}=\frac{\left(\pi / 2+\gamma_{2}\right) \tau_{1 \max }-\gamma_{1} \tau_{3 \max }}{\tau_{1 \max }+\tau_{3 \max }}
$$

As shown in Fig. 2, in accordance with the geometric relations of the minimum cutting thickness and the stagnation point, the minimum cutting thickness can be

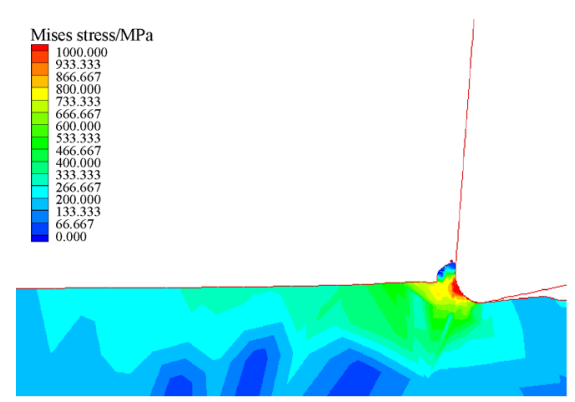

(a)

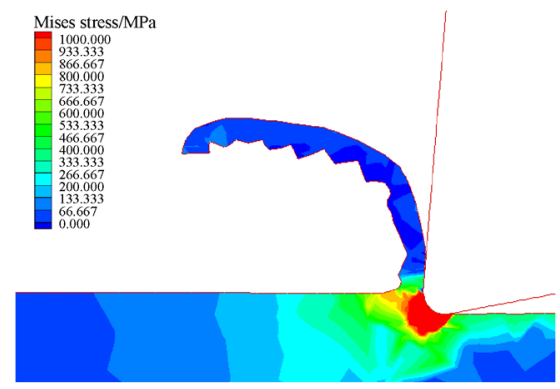

(b)

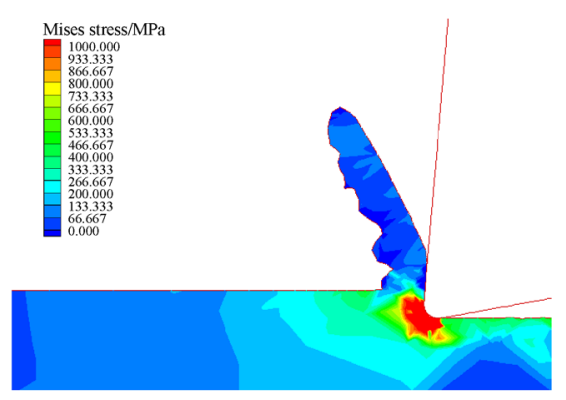

(c)

Fig. 7 Stress distribution in cutting process: (a) $h=0.5 r_{\mathrm{n}}$, (b) $h=r_{\mathrm{n}}$, and (c) $h=2 r_{\mathrm{n}}$. 
found as follows:

$$
d_{\min }=\left(1-\sin \gamma_{\mathrm{s}}\right) r_{\mathrm{n}} .
$$

In consideration of material properties and tool geometries, the modeling of uncut thickness is found and $\tau_{\max }$ equals $655 \mathrm{MPa}$, as previously reported [16]. The objective of this study is to verify the correctness of the modeling of uncut thickness in TC4 machining by applying different friction coefficients in simulations and comparing the simulation results with experimental results.

\section{Simulations on micro cutting}

\subsection{Determination of the stagnation point}

The commercial finite element software Third Wave AdvantEdge is used to model metal cutting. The workpiece material is TC4, and its chemical composition is shown in Table 1. TC4 is one type of alloy with high strength, superior stability, toughness, plasticity, and high temperature deformation. These parameters are important constituents when evaluating the mechanical properties of materials. The physical and mechanical properties of TC4 are shown in Table 2. A series of cutting simulations is typically used to study the stagnation point: Cutting speed of $300 \mathrm{~mm} / \mathrm{min}$, cut set depth of $0.02 \mathrm{~mm}$, and tool edge radius of $0.02 \mathrm{~mm}$. The parameters of the stress distributions on the interface between the tool and the workpiece are calculated using the formula in Section 2, and the friction coefficient has been inserted into the finite element method (FEM) modeling.

In consideration of the friction around the cutting zone, the simulated stagnation points at different rake and
Table 1 Chemical composition of titanium alloy TC4

\begin{tabular}{lc}
\hline Chemical composition & Mass content/\% \\
\hline Al & 6.160 \\
V & 3.950 \\
$\mathrm{Fe}$ & 0.030 \\
$\mathrm{C}$ & 0.040 \\
$\mathrm{~N}$ & 0.014 \\
$\mathrm{H}$ & 0.005 \\
$\mathrm{O}$ & 0.060 \\
$\mathrm{Ti}$ & Balance \\
\hline
\end{tabular}

clearance angles are shown in Figs. 8 and 9, respectively. The simulation and theoretical values of stagnation points at different rake and clearance angles are shown in Figs. 10(a) and 10(b). The stagnation points in the theoretical model and simulation show a close match under four rake and clearance angles, indicating that the FEM modeling for calculating the stagnation point is accurate.

The simulation results regarding stagnation points at different tool edge radii are shown in Fig. 11. In the four sets of simulations, the location of stagnation point is insensitive to tool edge radius. Experiments using different rake angles and a clearance angle of $5^{\circ}$ are conducted.

\subsection{Determination of the minimum cutting thickness}

The simulation model of the minimum cutting thickness is shown in Fig. 12. A series simulation is used to study the minimum cutting thickness: Cutting depth range of $0-f(f=$ $0.1 \mathrm{~mm}$ ), cutting speed of $300 \mathrm{~mm} / \mathrm{min}$, tool edge radius of $0.02 \mathrm{~mm}$, rake angle of $5^{\circ}$, and clearance angle of $5^{\circ}$.

Figure 13 presents the cutting forces with different rake

Table 2 Physical and mechanical properties of titanium alloy TC4

\begin{tabular}{lccccc}
\hline Density $/\left(\mathrm{kg} \cdot \mathrm{m}^{-3}\right)$ & Melting point $/{ }^{\circ} \mathrm{C}$ & Specific heat $\left(\mathrm{J} \cdot \mathrm{kg}^{-1} \cdot{ }^{\circ} \mathrm{C}^{-1}\right)$ & Thermal conductivity $/\left(\mathrm{W} \cdot \mathrm{m}^{-1} \cdot{ }^{\circ} \mathrm{C}^{-1}\right)$ & Elasticity modulus $/ \mathrm{GPa}$ & Poisson's ratio \\
\hline 4500 & 1668 & 612 & 7.955 & 114 \\
\hline
\end{tabular}

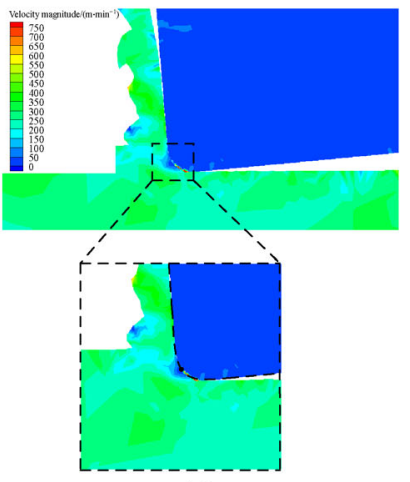

(a)

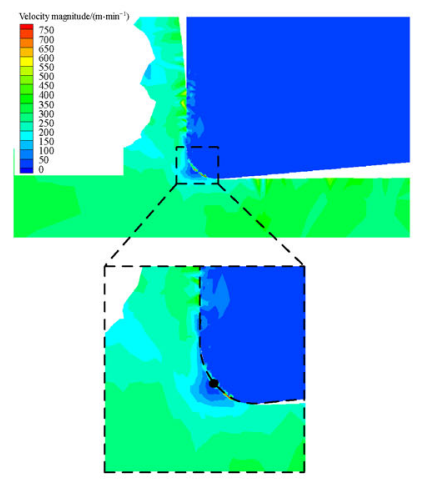

(b)

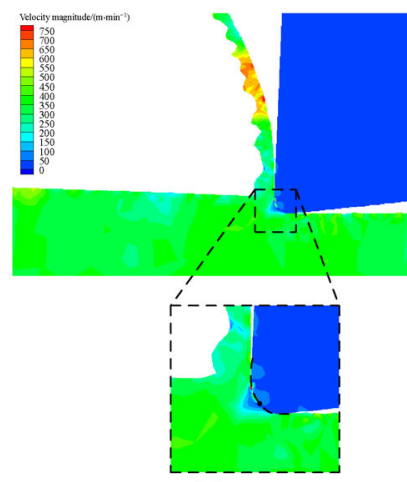

(c)

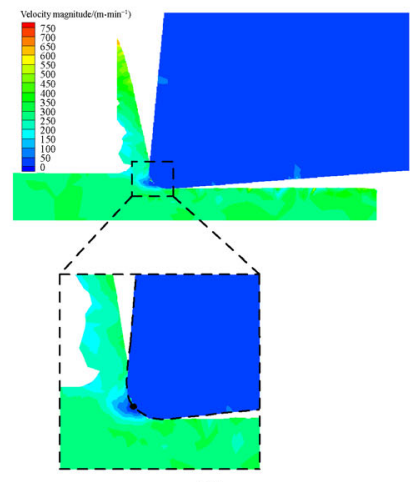

(d)

Fig. 8 Stagnation angle at different rake angles: (a) $\gamma_{1}=5^{\circ}$, (b) $\gamma_{1}=0^{\circ}$, (c) $\gamma_{1}=3^{\circ}$, and (d) $\gamma_{1}=5^{\circ}$. 


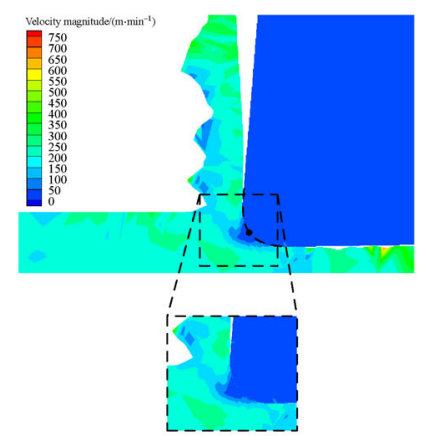

(a)

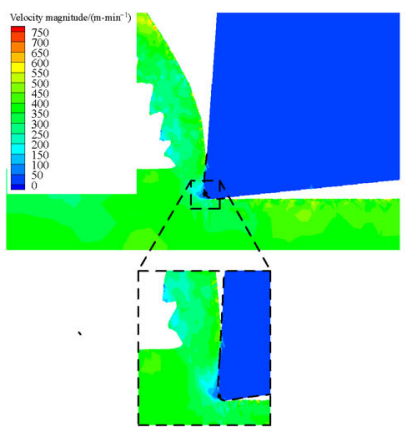

(b)

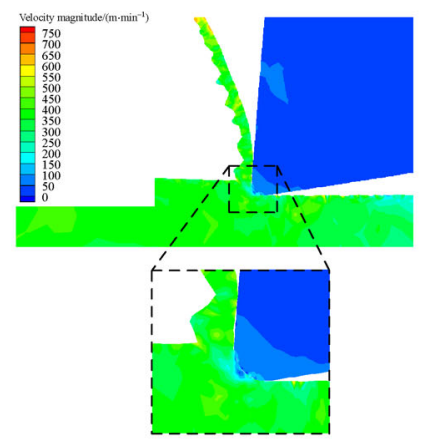

(c)

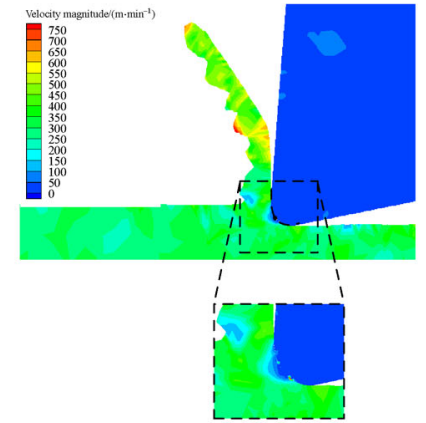

(d)

Fig. 9 Stagnation angle at different clearance angles: (a) $\gamma_{2}=0^{\circ}$, (b) $\gamma_{2}=5^{\circ}$, (c) $\gamma_{2}=8^{\circ}$, and (d) $\gamma_{2}=10^{\circ}$.

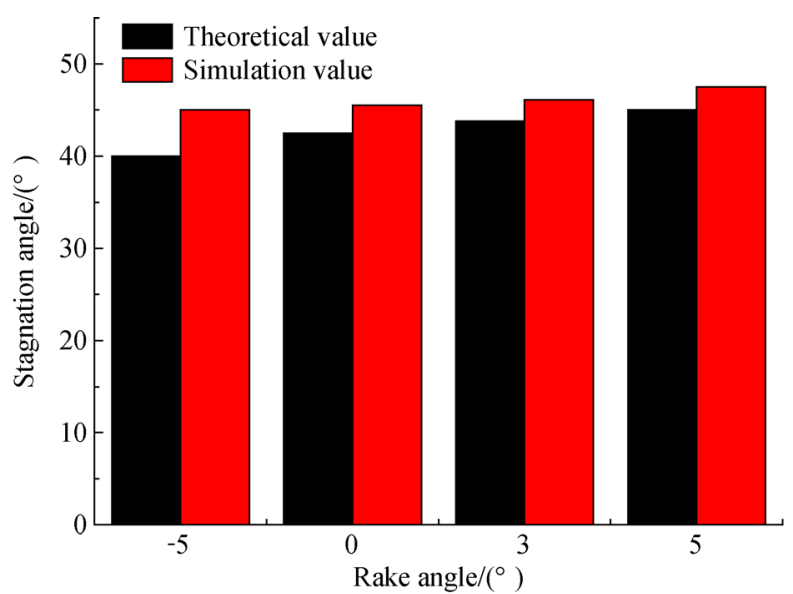

(a)

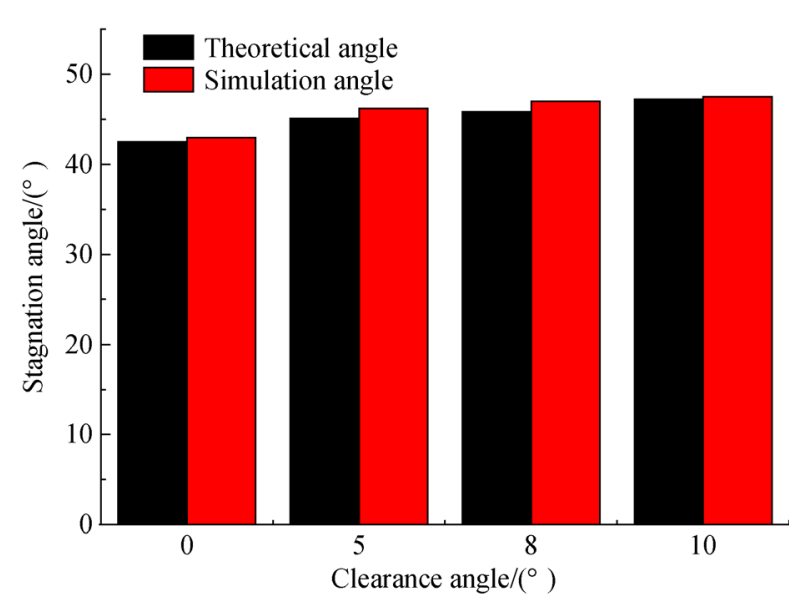

(b)

Fig. 10 Theoretical and simulation values of the stagnation angle at (a) different rake angles and (b) different clearance angles.

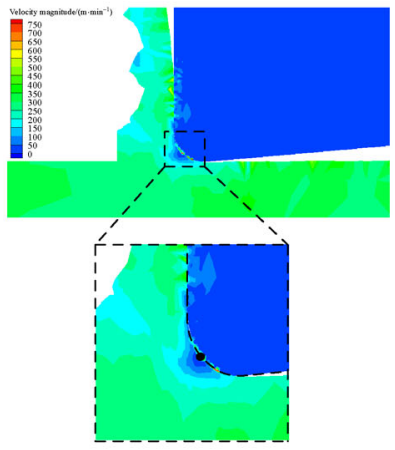

(a)

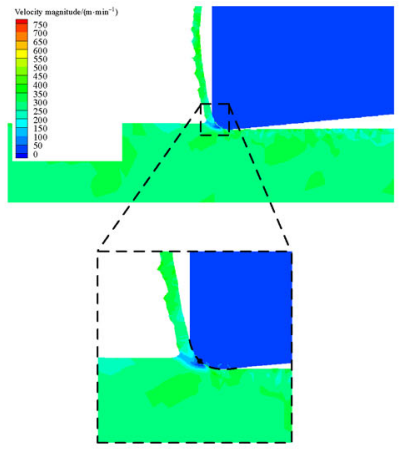

(b)

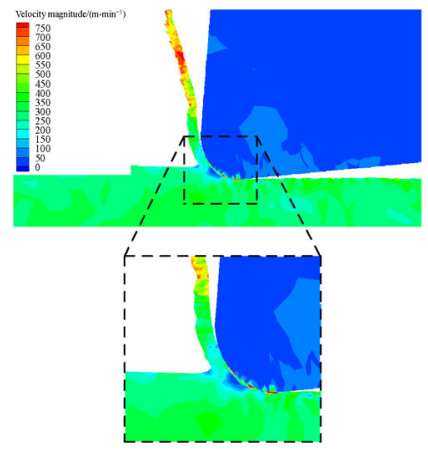

(c)

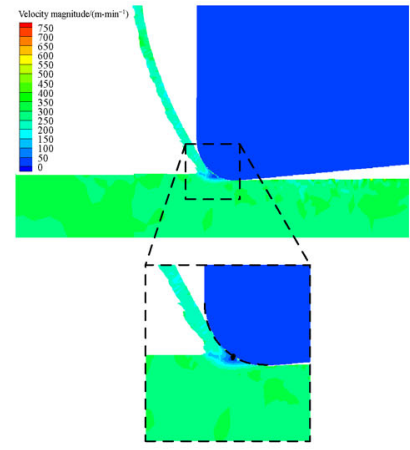

(d)

Fig. 11 Stagnation angle at different tool edge radii: (a) $0.02 \mathrm{~mm}$, (b) $0.05 \mathrm{~mm}$, (c) $0.07 \mathrm{~mm}$, and (d) $0.1 \mathrm{~mm}$.

angles. The turning point can be clearly observed in the curve of the cutting force. The minimum cutting thickness can be calculated through the location of the turning point.

\section{Experiments on micro cutting}

Micro cutting experiments are carried out to verify the 


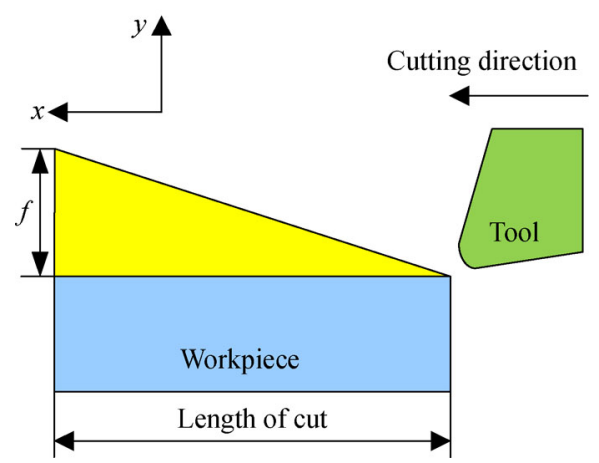

Fig. 12 Illustration of FEM model of micro cutting.

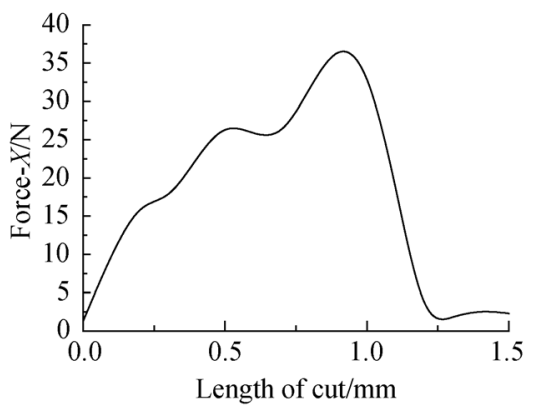

(a)

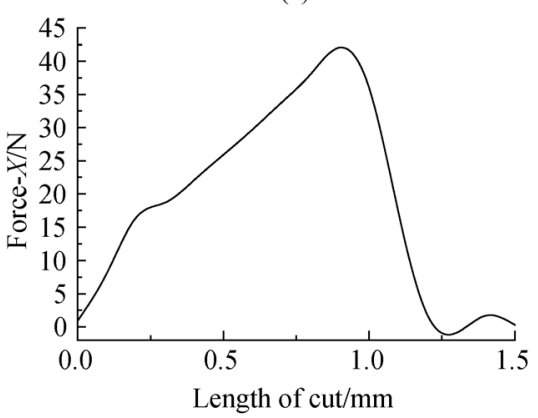

(b)

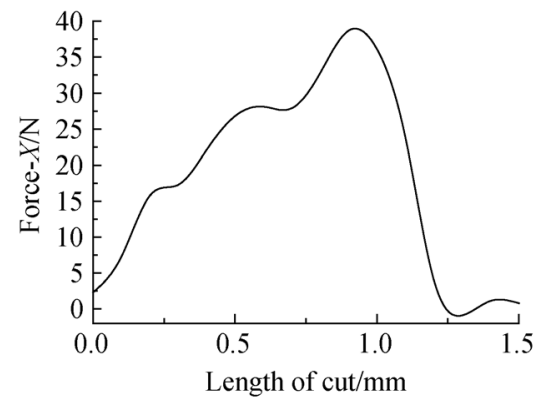

(c)

Fig. 13 Simulations of the force variation at different fake angles: (a) $\gamma_{1}=5^{\circ}$, (b) $\gamma_{1}=0^{\circ}$, and (c) $\gamma_{1}=5^{\circ}$.

model by comparing the predicted results with experimental data. The experimental setup is shown in Fig. 14. Further, the cutting forces at different rake angles are shown in Fig. 15. The minimum cutting thickness can be calculated through the inflection point, and the comparison

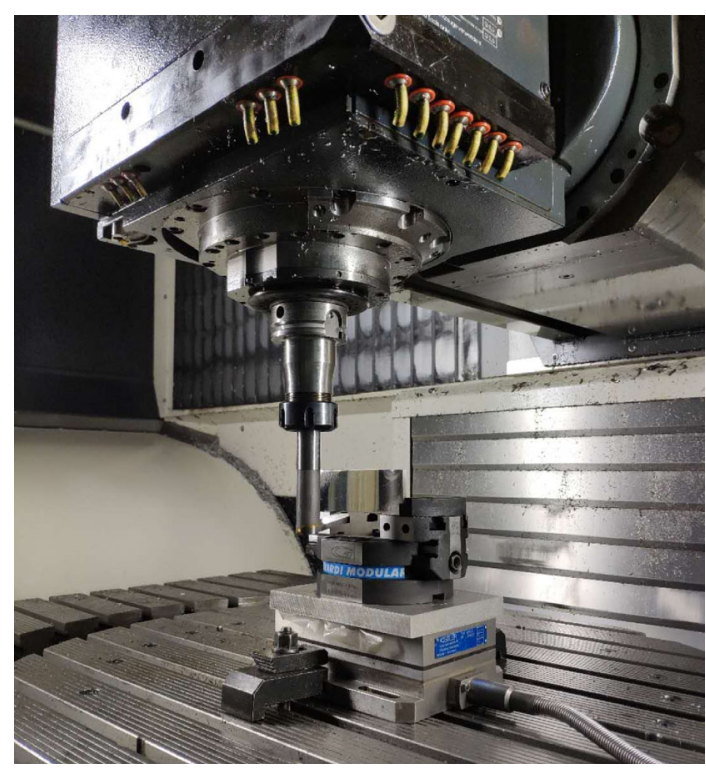

Fig. 14 Experimental setup of micro cutting.

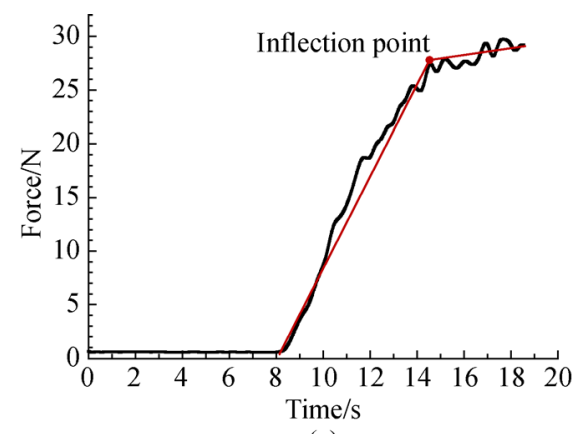

(a)

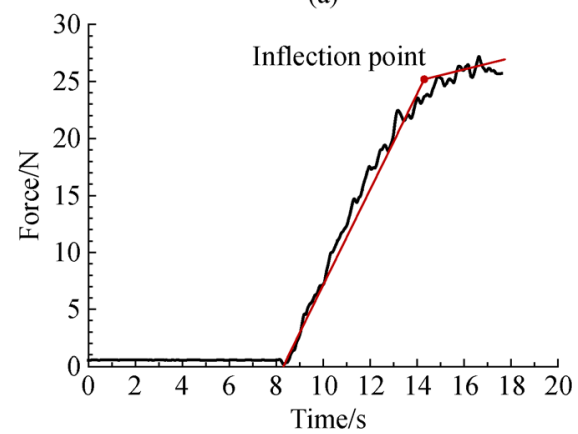

(b)

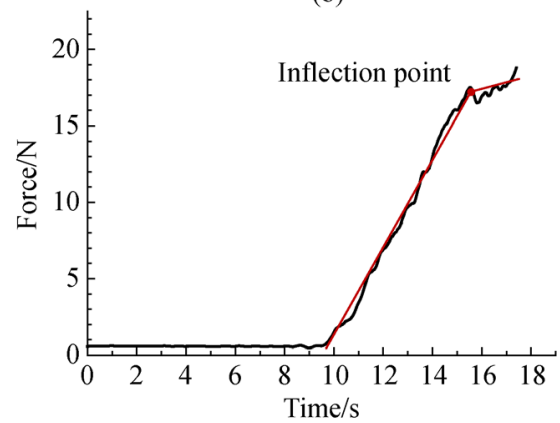

(c)

Fig. 15 Experimental cutting forces at different fake angles: (a) $\gamma_{1}=5^{\circ}$, (b) $\gamma_{1}=0^{\circ}$, and (c) $\gamma_{1}=5^{\circ}$. 
of the minimum cutting thickness between simulations and experiments is shown in Fig. 16.

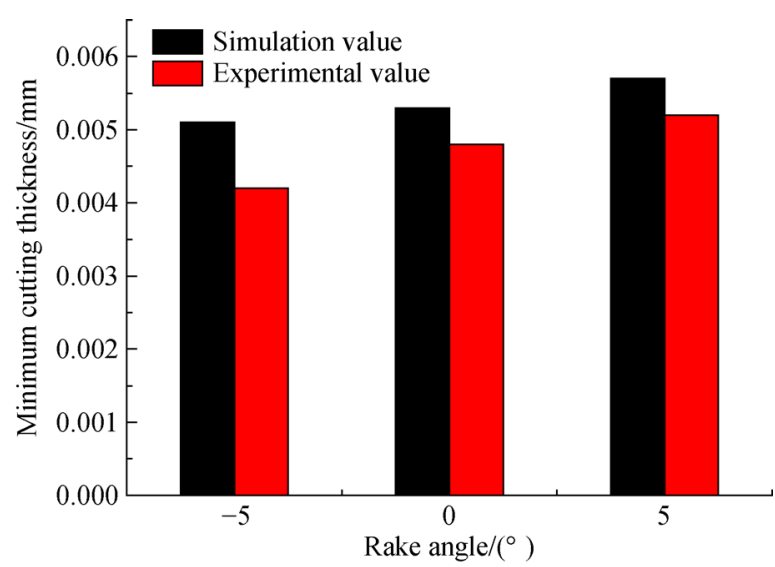

Fig. 16 Experimental and simulation values of the minimum cutting thickness at different rake angles.

The minimum cutting thickness in micro cutting experiments and simulations shows a close match under the four rake angles, indicating that the proposed friction model is a potential method for predicting the minimum cutting thickness.

\section{Conclusions}

Experiments and simulations are conducted to study the minimum cutting thickness in micro cutting. The following conclusions can be drawn:

(1) The cutting tool edge radius strongly affects the distributions of the normal and shear stress around the cutting zone, determining the minimum cutting thickness in micro cutting.

(2) The stagnation point location is determined by modeling the friction from analyzing the material flow and material separation around the tool-workpiece interface friction around the cutting zone in the micro cutting.

(3) Based on the friction modeling and the stagnation point analysis, a theoretical model of the minimum cutting thickness is established, which is verified by micro cutting experiments.

Open Access This article is licensed under a Creative Commons Attribution 4.0 International License, which permits use, sharing, adaptation, distribution and reproduction in any medium or format, as long as you give appropriate credit to the original author(s) and the source, provide a link to the Creative Commons licence, and indicate if changes were made.

The images or other third party material in this article are included in the article's Creative Commons licence, unless indicated otherwise in a credit line to the material. If material is not included in the article's Creative Commons licence and your intended use is not permitted by statutory regulation or exceeds the permitted use, you will need to obtain permission directly from the copyright holder.

To view a copy of this licence, visit http://creativecommons.org/licenses/ by $/ 4.0 /$.

\section{References}

1. Son S M, Lim H S, Ahn J H. Effects of the friction coefficient on the minimum cutting thickness in micro cutting. International Journal of Machine Tools and Manufacture, 2005, 45(4-5): 529-535

2. Coelho R T, Diniz A E, da Silva T M. An experimental method to determine the minimum uncut chip thickness in orthogonal cutting. Procedia Manufacturing, 2017, 10: 194-207

3. Dib M H M, Duduch J G, Jasinevicius R G. Minimum chip thickness determination by means of cutting force signal in micro endmilling. Precision Engineering, 2018, 51: 244-262

4. Agmell M, Johansson D, Laakso S V A, et al. The influence the uncut chip thickness has on the stagnation point in orthogonal cutting. Procedia CIRP, 2017, 58: 13-18

5. Atlati S, Moufki A, Nouari M, et al. Interaction between the local tribological conditions at the tool-chip interface and the thermomechanical process in the primary shear zone when dry machining the aluminum alloy. Tribology International, 2017, 105: 326-333

6. Ee K C, Dillon O W Jr, Jawahir I S. Finite element modeling of residual stresses in machining induced by cutting using a tool with finite edge radius. International Journal of Mechanical Sciences, 2005, 47(10): 1611-1628

7. Amontons G. Resistance caused in machines. Journal of Japanese Society of Tribologists, 1999, 44: 236-241 (in French)

8. Zorev $\mathrm{N} \mathrm{N}$. Interrelationship between shear processes occurring along tool face and on shear plane in metal cutting. In: Proceedings of the International Production Engineering Research Conference. Pittsburg, 1963

9. Shaw M C. Contact problems in cutting and grinding. In: Attia M H, Komanduri R, eds. PED-Vol. $67=$ Trib-Vol.4, Contact Problems and Surface Interaction in Manufacturing and Tribological Systems. New York: ASME, 1993, 143-149

10. Moufki A, Molinari A, Dudzinski D. Modeling of orthogonal cutting with a temperature dependent friction law. Journal of the Mechanics and Physics of Solids, 1998, 46(10): 2103-2138

11. Wallace P W, Boothroyd G. Tool forces and tool-chip friction in orthogonal machining. Journal of Mechanical Engineering Science, 1964, 6(1): 74-87

12. Strenkowski J S, Moon K J. Finite element prediction of chip geometry and tool/workpiece temperature distributions in orthogonal metal cutting. Journal of Engineering for Industry, 1990, 112(4): 313-318

13. Lin Z C, Lo S P. Ultra-precision orthogonal cutting simulation for oxygen-free high-conductivity copper. Journal of Materials Processing Technology, 1997, 65(1-3): 281-291

14. Liu C R, Guo Y B. Finite element analysis of the effect of sequential cuts and tool-chip friction on residual stresses in a machined layer. International Journal of Mechanical Sciences, 2000, 42(6): 10691086

15. Zhang B, Bagchi A. Finite element simulation of chip formation and comparison with machining experiment. Journal of Engineering for Industry, 1994, 116(3): 289-297

16. Yang X, Liu C R. A new stress-based model of friction behavior in machining and its significant impact on residual stresses computed by finite element method. International Journal of Mechanical Sciences, 2002, 44(4): 703-723 